\title{
Photochemical reactivity of zinc tetraphenylporphyrin induced by nonstoichiometric CdS nanoparticles in 2-propanol
}

\author{
Alex V. Isarov and John Chrysochoos \\ Department of Chemistry, The University of Toledo, Toledo, Ohio 43606, USA
}

\begin{abstract}
The photoreactivity of zinc tetraphenylporphyrin (ZnTPP) in the presence of photoexcited CdS nanoparticles and molecular oxygen in 2-propanol has been revisited. The photodecomposition of ZnTPP in 2-propanol, in the presence of $\mathrm{CdS}\left(\mathrm{e}^{-} \mathrm{CB} / \mathrm{h}^{+} \mathrm{VB}\right)$ and molecular oxygen, is linked to isopropyl free radicals formed by both hole transfer from $\mathrm{CdS}\left(\mathrm{h}^{+} \mathrm{VB}\right)$ to $\left(\mathrm{CH}_{3}\right)_{2} \mathrm{CHOH}$ and the reaction of superoxide ion $\left(\mathrm{O}_{2}{ }^{-}\right)$ with 2-propanol. Isopropyl free radicals react with ZnTPP, leading to the formation of ZnTPP ${ }^{\bullet-}$. Intermediate paramagnetic species monitored by EPR spectroscopy $(g=2.0029, \Delta H=5.7 \mathrm{G})$ were characterized as superoxides formed in the reaction of $\mathrm{ZnTPP}^{\bullet-}$ with $\mathrm{O}_{2}$. Further transformations of such EPR-active species lead to the formation of diamagnetic intermediate photoproducts of ZnTPP observed by absorption and emission spectroscopy.
\end{abstract}

\section{INTRODUCTION}

Photocatalytic reactions initiated by colloidal semiconductor nanoparticles have been studied extensively during the past two decades [1]. Light-induced electron/hole pair formation in semiconductor particles, accompanied by subsequent interfacial electron (hole) transfer, has always been considered as the first step of the photocatalytic action of semiconductor nanoparticles $[1,2]$. Primary photoproducts resulting from interfacial electron (hole) transfer, i.e. radical ions, undergo further transformations leading to the formation of final photoproducts.

Although semiconductor-assisted phototransformations of many organic and organometallic compounds have been studied [1, 2], very few studies have been reported dealing with the photochemistry of metalloporphyrins in the presence of semiconductor nanoparticles [3]. Semiconductor-assisted phototransformations of porphyrins and metalloporphyrins are of significant interest because of potential practical applications of porphyrin/semiconductor systems [4, 5]. Ellis and co-workers have demonstrated that metalloporphyrin films on the surface of II-VI semiconductors can be used as transducer films for chemical sensing [4]. Furthemore, porphyrins and metalloporphyrins have been looked upon as potential photosensitizers [5].

Among the metalloporphyrins used in the photochemical studies mentioned above [3], zinc tetraphenylporphyrin (ZnTPP) was studied in more detail in the presence of electronically excited CdS nanoparticles and molecular oxygen [3, (a)-(d)], leading to the formation of open-chain tetrapyrrole compounds and their metal complexes [3, (d)].

In spite of the photochemical reactivity of ZnTPP in the presence of CdS nanoparticles and molecular oxygen, it is very stable photochemically in the absence of molecular oxygen, under otherwise identical conditions. Very limited photoreactivity was observed under prolonged irradiation (1-2 hours), in such conditions, leading to the formation of traces of reduced porphyrins $\left(\mathrm{ZnTPPH}_{2}\right.$ and $\mathrm{ZnTPPH}(\mathrm{OH})$ ) [3, (d)]. Furthemore, the recombination luminescence of $\mathrm{CdS}\left(\mathrm{e}^{-}\right.$tr. $/ \mathrm{h}^{+}$tr. $)$nanoparticles in solution was found to be quenched effectively by ZnTPP, both in the absence and presence of molecular oxygen [3, (a)-(c)]. The lack of photoreactivity of ZnTPP in the presence of deaerated CdS nanoparticles, in spite of the efficient recombination luminescence quenching of $\mathrm{CdS}\left(\mathrm{e}^{-} / \mathrm{h}^{+}\right)$by ZnTPP under the same conditions, was attributed to efficient back electron transfer [3, (a),(b)].

The nature of photoreactivity of ZnTPP in the presence of CdS nanoparticles and molecular oxygen is not clear. The present study is devoted to the investigation of the initial steps of this process by detecting the intermediate species formed. The formation of paramagnetic species brought about by irradiation of mixtures of ZnTPP and CdS nanoparticles was monitored by EPR. The role of molecular oxygen on the photodecomposition of ZnTPP under these conditions was investigated.

Irradiation of CdS nanoparticles $\left(h v>E_{g}\right)$ in the presence of ZnTPP may lead to CdS-induced photochemistry of ZnTPP via both electron and hole transfer. To distinguish between the contribution of photogenerated electrons and holes in the photochemistry of ZnTPP appropriate EPR studies were undertaken in the presence and absence of molecular oxygen and under conditions controlling the availability of photogenerated conduction band electrons $\left(\mathrm{e}^{-} \mathrm{CB}\right)$. 


\section{EXPERIMENTAL}

Cadmium sulfide nanoparticles were prepared in 2propanol at $-78{ }^{\circ} \mathrm{C}$, in the absence of any stabilizers, using well-established literature techniques of "arrested precipitation" [6]. Values of their band gap energies ranged from 3.0 to $3.1 \mathrm{eV}$ [3, (e)]. Preparation details can be found elsewhere [3, (e)].

Ultraviolet and visible absorption spectra were recorded with a Hewlett-Packard 8452A Diode Array spectrophotometer. Luminescence spectra were recorded with an Aminco-Bowman spectrophotofluorimeter.

Samples of CdS nanoparticles were irradiated with an UV light source (Hg lamp) through a $10 \mathrm{~cm}$ water filter and an Oriel color glass filter (Cat \#59810) with a maximum transparency of $47 \%$ at $360 \mathrm{~nm}$ with $5 \%$ cutoffs at 310 and $395 \mathrm{~nm}$. The color filter was selected to avoid excitation of ZnTPP at $422 \mathrm{~nm}$ (Soret band). At low concentrations of ZnTPP $\left(2 \times 10^{-6} \mathrm{M}\right)$, an Oriel neutral density filter (Cat \#59705, optical density about 1.41.5 within the range $300-700 \mathrm{~nm}$ ) was also used. The distance between the lamp and the sample was kept at $35 \mathrm{~cm}$ in all experiments. The photochemical transformations of the irradiated samples were monitored by UV/Vis absorption spectroscopy and EPR spectroscopy.

EPR measurements were carried out using a Bruker ESP $300 \mathrm{E}$ spectrometer. Standard EPR tubes containing mixtures of ZnTPP and CdS nanoparticles were placed into a quartz Dewar flask and irradiated at room temperature. At the end of the irradiation period the Dewar flask was filled with liquid nitrogen and the sample was transferred to the EPR finger Dewar flask, which was already placed in the EPR spectrometer cavity and filled with liquid nitrogen. The $g$-value for the radical species was determined by comparison with the $g$-value of DPPH (2.0037).

Zinc tetraphenylporphyrin (ZnTPP), used in this study, was synthesized from purified $\mathrm{H}_{2}$ TPP (chlorin free) [7] and zinc acetate, using standard literature preparation and chromatographic purification methods [8]. Addition of $\mathrm{Eu}^{3+}$-ions to the colloidal solution of CdS nanoparticles was carried out using a solution of freshly prepared $\mathrm{Eu}\left(\mathrm{ClO}_{4}\right)_{3}$ in 2-propanol. All other chemicals used were of the highest purity available commercially.

\section{RESULTS AND DISCUSSION}

Irradiation of $2 \times 10^{-4} \mathrm{M}$ CdS nanoparticles at $365 \mathrm{~nm}$ in the presence of $2 \times 10^{-6} \mathrm{M}$ ZnTPP and molecular oxygen led to photochemical changes of ZnTPP illustrated in Figure 1. The concentration of ZnTPP used was particularly low to make certain that all photons at $365 \mathrm{~nm}$ were absorbed by CdS and to monitor the photochemical changes of ZnTPP via its Soret band (422 nm). The photodecomposition of ZnTPP was evident by the re-

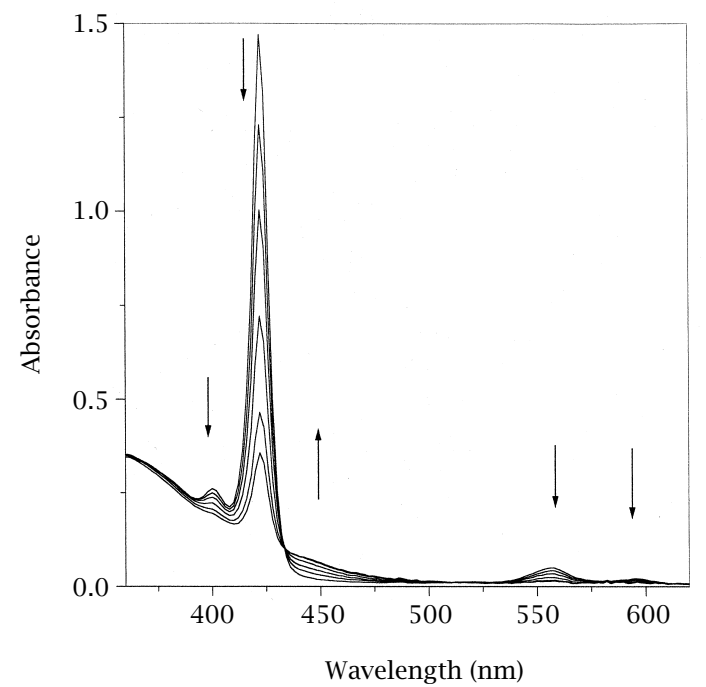

Figure 1. Spectral changes during the photodecomposition of ZnTPP $\left(2 \times 10^{-6} M\right.$, air saturated solution $)$ in the presence of $2 \times 10^{-4} \mathrm{M}$ CdS nanoparticles in 2-propanol. Irradiation at $365 \mathrm{~nm}$. The arrows indicate the direction of change with time: 0, 1, 2, 4, 6, 8 min.

duction of both its Soret band (422 nm) and its Q-bands $(556 \mathrm{~nm}$ and $596 \mathrm{~nm})$. The presence of a well-defined isobestic point at $436 \mathrm{~nm}$ indicates that the changes recorded are linked directly to ZnTPP in a $1: 1$ ratio. Figure 2 shows the dependence of the absorbance of ZnTPP at $422 \mathrm{~nm}$ upon the irradiation time in the presence of $\mathrm{O}_{2}$ and in the absence of CdS nanoparticles (a), in the presence of CdS and in the absence of $\mathrm{O}_{2}(\mathrm{~b})$ and in the presence of both CdS nanoparticles and $\mathrm{O}_{2}$ (c). The additional data shown in Figure 2 are linked to the presence of $\mathrm{Eu}^{3+}$ and will be discussed later on.

Whereas ZnTPP is completely stable photochemically in air-saturated 2-propanol solutions (under the experimental conditions employed in this study) and in deaerated solutions in the presence of CdS nanoparticles, it undergoes extensive photodecomposition in the presence of both CdS nanoparticles and molecular oxygen. The appearance of new absorption bands in the spectral ranges of $450-500 \mathrm{~nm}$ and $630-850 \mathrm{~nm}$, although noticeable in Figure 1 (i.e. $450-500 \mathrm{~nm}$ ), it becomes much more unambiguous at higher concentrations of ZnTPP, namely at $1 \times 10^{-4} \mathrm{M}$ (Figure 3 ). It should also be pointed out that the characteristic absorption bands of the irradiated mixture in the red region of the spectrum do not appear in the absence of dissolved molecular oxygen under the concentration conditions shown in Figure 3. In addition, irradiation of mixtures of CdS nanoparticles and ZnTPP in the presence of oxygen at $\lambda>515 \mathrm{~nm}$, a wavelength range in which ZnTPP absorbs light effectively (via its Q-bands) but CdS nanoparticles are completely transparent, did not lead to any photochemical activity [3, (d)]. 


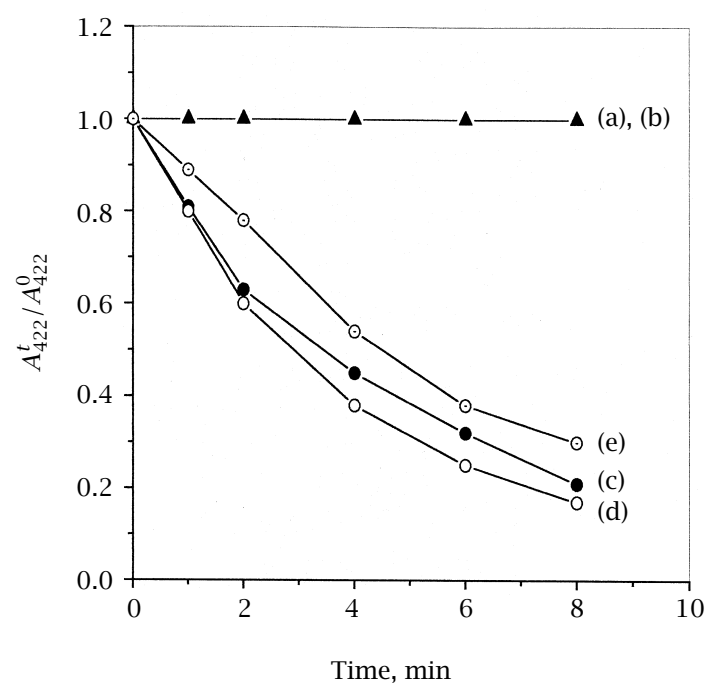

Figure 2. Relative absorptivity of $2 \times 10^{-6} \mathrm{M}$ zinc tetraphenylporphyrin at $422 \mathrm{~nm}$ (Soret band) vs. irradiation time: (a) air-saturated, in the absence of $\mathrm{CdS}$ nanoparticles; (b) deaerated, in the presence of $2 \times 10^{-4} \mathrm{M} \mathrm{CdS}$ nanoparticles; (c) air-saturated, in the presence of $2 \times$ $10^{-4}$ MCdS nanoparticles; (d) air-saturated, in the presence of $2 \times 10^{-4} \mathrm{MCdS}$ nanoparticles and $5 \times 10^{-6} \mathrm{MEu}^{3+}$; (e) airsaturated, in the presence of $2 \times 10^{-4} \mathrm{MCdS}$ nanoparticles and $4 \times 10^{-5} \mathrm{M} \mathrm{Eu}^{3+}$. Irradiation at $365 \mathrm{~nm}$.

The observations depicted in Figure 3 may be questioned due to of the significant absorption of photons at $365 \mathrm{~nm}$ by ZnTPP at such high concentrations. Based upon the absorptivities of CdS nanoparticles and ZnTPP in 2-propanol at $365 \mathrm{~nm}$, about 50\% of the photons ab-

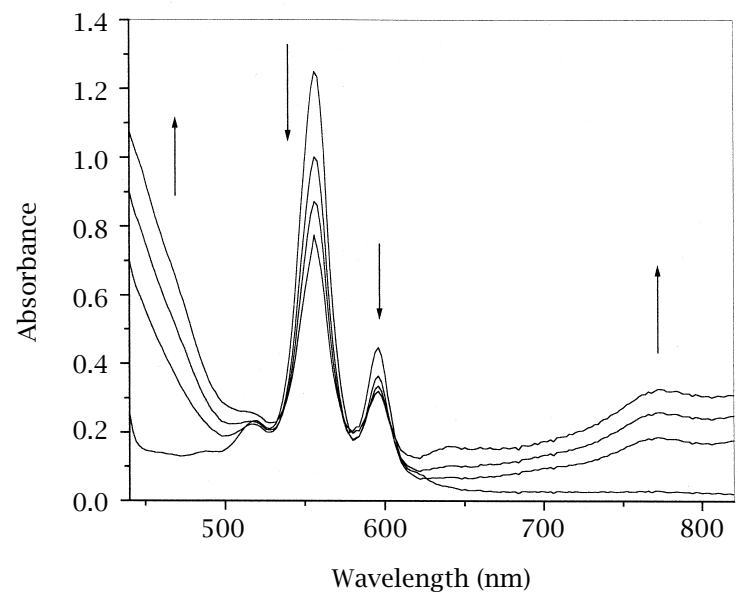

Figure 3. Spectral changes during the photodecomposition of ZnTPP $\left(1 \times 10^{-4} \mathrm{M}\right.$, air saturated solution) in the presence of $2 \times 10^{-4} \mathrm{M} \mathrm{CdS}$ nanoparticles in 2-propanol. Irradiation at $365 \mathrm{~nm}$. The arrows indicate the direction of change with time: 0, 5, 10, $20 \mathrm{~min}$. sorbed are taken up by ZnTPP. Therefore, one may rationalize that the observations shown in Figure 3 are linked, fully or partially, to the reactivity of photoexcited ZnTPP in the presence of CdS nanoparticles. However, as it was briefly mentioned above, deaerated and air-saturated mixtures of ZnTPP and CdS nanoparticles in 2-propanol, excited with a W-lamp through a long pass color glass filter $\left(\lambda_{\text {tr. }}>515 \mathrm{~nm}\right.$, Oriel 59494$)$, led to negligible changes in the absorption spectrum of ZnTPP (about 3\% destruction) after prolonged irradiation (about 2 hours) [3, (d)]. Such minor changes were not permanent. Therefore, excited ZnTPP in the presence of CdS is not responsible for the spectral changes outlined in Figure 3.

Irradiation of $2 \times 10^{-4} \mathrm{M}$ CdS nanoparticles at $365 \mathrm{~nm}$ and at room temperature, in the presence of $1 \times 10^{-4} \mathrm{M}$ ZnTPP and molecular oxygen, gave rise to the formation of paramagnetic species monitored by EPR. A typical EPR spectrum (Figure 4(a)) consists of a Gaussian shape singlet with $g=2.0029$ and a total line width [9] of $22 \mathrm{G}$ (the width between the inflection points is equal to $5.7 \mathrm{G}$ ). The paramagnetic species responsible for this EPR signal were not very stable at room temperature (they disappeared in 1-2 minutes), but they were quite stable at $77 \mathrm{~K}$. Therefore, samples were irradiated at room temperature and they were rapidly brought to $77 \mathrm{~K}$. The intensity of the EPR signal was found to be dependent on the concentration of ZnTPP, ranging from $4 \times 10^{-5} \mathrm{M}$ to $4 \times 10^{-4} \mathrm{M}$, and the irradiation time. Optimum conditions for EPR signals with maximum intensities were as follows: $[\mathrm{CdS}]=2 \times 10^{-4} \mathrm{M}$, [ZnTPP] $=1 \times 10^{-4} \mathrm{M}$, irradiation time $30 \mathrm{~s}$. All EPR spectra were recorded under these conditions.

Deaeration of the mixture of CdS nanoparticles and ZnTPP before irradiation led to a drastic reduction of the EPR signal (Figure 4(b)). An extremely weak EPR signal observed in this case may be due to the presence of residual $\mathrm{O}_{2}$, adsorbed onto $\mathrm{CdS}$ nanoparticles, which is very difficult to remove completely. Control experiments of $1 \times 10^{-4} \mathrm{M} \mathrm{ZnTPP}$ in 2-propanol without CdS nanoparticles (air-saturated) and $2 \times 10^{-4} \mathrm{M}$ CdS nanoparticles in 2-propanol without ZnTPP (airsaturated), did not lead to any detectable EPR signals under irradiation at $365 \mathrm{~nm}$. Therefore, the EPR signal detected is not attributed to either $\mathrm{ZnTPP}^{\bullet-}$ or $\mathrm{O}_{2}{ }^{-}$, which are the most likely radical ions to be formed in the control experiments. If, on the other hand, 2-propanol undergoes decomposition in the control experiments leading to appropriate radical ions, their formation must be either negligible or their lifetime must be extremely short to have avoided detection by EPR. Consequently, the EPR signal detected requires the presence of both CdS $\left(\mathrm{e}^{-} / \mathrm{h}^{+}\right)$, ZnTPP and $\mathrm{O}_{2}$.

Attempts to obtain EPR signals by prolonged irradiation $(60 \mathrm{~min})$ of frozen mixtures of ZnTPP and CdS nanoparticles in the presence of $\mathrm{O}_{2}$ failed to yield any detectable EPR signals. This implies that the 

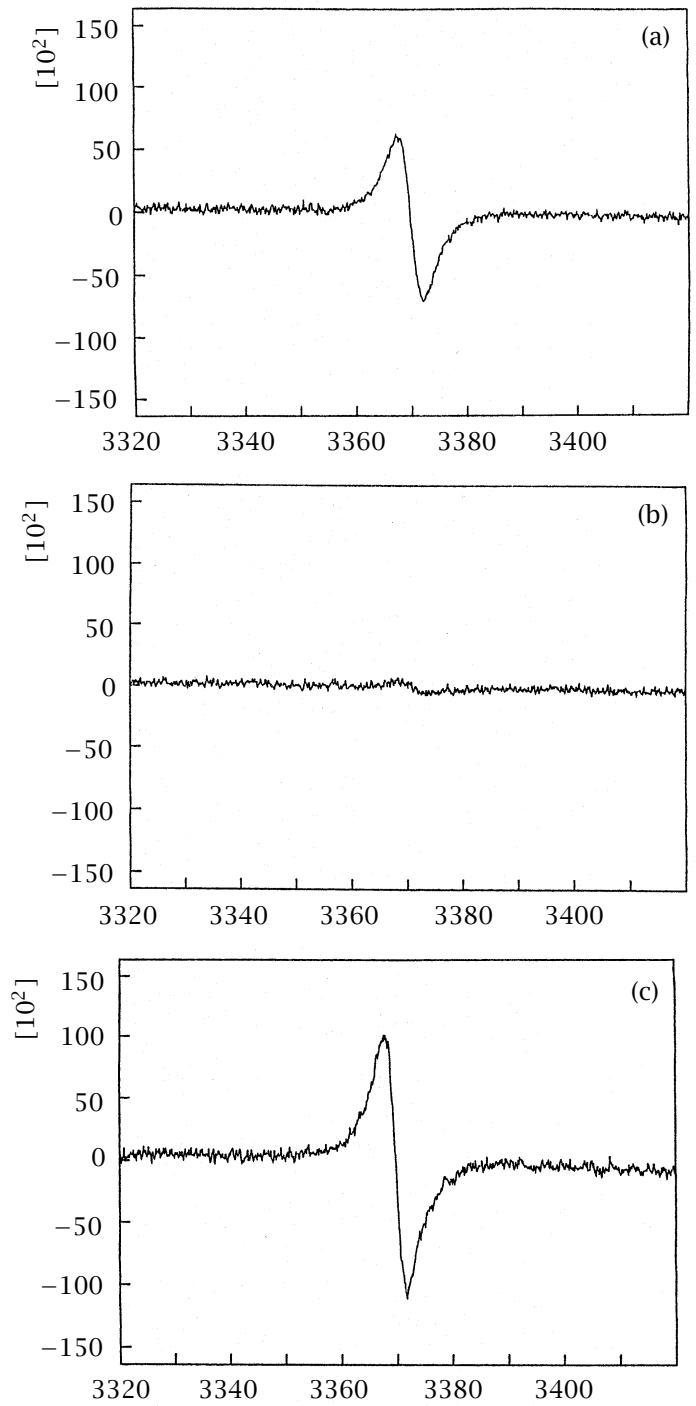

Figure 4. EPR spectra of irradiated (365 $\mathrm{nm}$ ) reaction mixtures of $1 \times 10^{-4} \mathrm{M} \mathrm{ZnTPP}$ and $2 \times 10^{-4} \mathrm{M} \mathrm{CdS}$ nanoparticles in 2-propanol. Reaction mixtures were frozen by liquid $\mathrm{N}_{2}$ at the end of irradiation period with the radiation still on: (a) air-saturated solution; (b) deaerated solution; (c) airsaturated solution in the presence of $4 \times 10^{-5} \mathrm{MEu}^{3+}$. Spectra were recorded at $77 \mathrm{~K}$.

reaction which leads to the formation of the paramagnetic species under consideration involves intermediate species in solution, subject to diffusion, rather than primary radical ions of ZnTPP adsorbed onto CdS nanoparticles.

To control the availability of photogenerated electrons $\left(\mathrm{e}^{-} \mathrm{CB}\right), \mathrm{Eu}^{3+}$ ions were used as electron acceptors (quenchers of recombination luminescence of $\mathrm{CdS}$ ). The quenching efficiency of $\mathrm{Eu}^{3+}$ ions on the recombination luminescence of $\mathrm{CdS}\left(\mathrm{e}^{-} / \mathrm{h}^{+}\right)$nanoparticles has been well documented [10]. Since $\mathrm{Eu}^{3+}$ ions compete against other electron acceptors for $\mathrm{e}^{-}$св, i.e. ZnTPP, they affect both the formation of radical ions and the $\mathrm{e}^{-}{ }_{\mathrm{CB}} / \mathrm{h}^{+} \mathrm{VB}$ recombination, both radiative and nonradiative. If $\mathrm{e}^{-}$Св is primarily responsible for the photochemistry of ZnTPP in the presence of CdS nanoparticles, via the formation of the $\mathrm{CdS}\left(\mathrm{h}^{+}\right)-\mathrm{ZnTPP}^{\bullet-}$ radical ion, the presence of $\mathrm{Eu}^{3+}$ as a competing electron acceptor would lead to the retardation of the electron-transfer process and consequently reduction of the photodecomposition of ZnTPP. On the other hand, an enhancement of the photodecomposition in the presence of $\mathrm{Eu}^{3+}$ would be expected if $\mathrm{h}^{+} \mathrm{VB}$ is primarily responsible for the photochemistry of ZnTPP due to the decrease of electron-hole recombination. It was found that $5 \times 10^{-6} \mathrm{M} \mathrm{Eu}^{3+}$ slightly accelerates the decomposition of ZnTPP induced by CdS nanoparticles (Figure 2(d)). The concentration of $\mathrm{Eu}^{3+}$ used was sufficient to quench about $50 \%$ of the original recombination luminescence of CdS nanoparticles (Figure 5(b)) indicating effective suppression of the $\mathrm{e}^{-}{ }_{\mathrm{CB}} / \mathrm{h}^{+}{ }_{\mathrm{VB}}$ recombination. Higher $\mathrm{Eu}^{3+}$ concentrations led to a slight deceleration of the decomposition of ZnTPP. For example, in the presence of $4 \times 10^{-5} \mathrm{M}$ $\mathrm{Eu}^{3+}$ the Soret band of ZnTPP decreases with irradiation time at a rate slightly lower than that in the absence of $\mathrm{Eu}^{3+}$ (Figure 2(e)). However, the recombination luminescence of $2 \times 10^{-4} \mathrm{M}$ CdS nanoparticles was totally wiped out in the presence of $4 \times 10^{-5} \mathrm{M} \mathrm{Eu}^{3+}$ ions, both in deaerated and air-saturated systems (Figure 5(c)). Therefore, $4 \times 10^{-5} \mathrm{M} \mathrm{Eu}^{3+}$ ions was considered sufficient to trap all $\mathrm{e}^{-}$св. The fact that considerable photoreactivity of ZnTPP was observed in the presence of $4 \times 10^{-5} \mathrm{M} \mathrm{Eu}^{3+}$, although the recombination luminescence of CdS nanoparticles was completely wiped out, implies that photogenerated holes are contributing to the photodecomposition of ZnTPP in the presence of CdS.

The presence of $1 \times 10^{-3} \mathrm{M} \mathrm{Eu}^{3+}$ was found to retard the photodecomposition of ZnTPP completely. However, the presence of $\mathrm{Eu}^{3+}$ in concentrations higher than $5 \times 10^{-5} \mathrm{M}$ leads to noticeable changes in the absorption spectra of CdS nanoparticles. This implies the incorporation of europium ions into the lattice of cadmium sulfide and the formation of ternary nanoparticles, namely $\mathrm{Cd}_{1-\mathrm{x}} \mathrm{Eu}_{\mathrm{x}} \mathrm{S}$, whose optical and spectroscopic properties may be very different from those of CdS. This assumption is supported by the absorption spectra of CdS nanoparticles in the presence of variable $\left[\mathrm{Eu}^{3+}\right]$ (Figure 6).

Typical EPR spectra of air-saturated mixtures of $2 \times 10^{-4} \mathrm{M} \mathrm{CdS}$ and $1 \times 10^{-4} \mathrm{M}$ ZnTPP in the presence of $4 \times 10^{-5} \mathrm{M} \mathrm{Eu}^{3+}$ are illustrated in Figure 4(c). The presence of $\mathrm{Eu}^{3+}$ enhanced the EPR signal of the irradiated mixture in the presence of $\mathrm{O}_{2}$ by approximately $100 \%$, but it did not affect the shape of the EPR spectrum. It should be pointed out that no EPR signal was observed in the presence of $\mathrm{Eu}^{3+}$ and in the absence of $\mathrm{O}_{2}$ under otherwise identical conditions. In addition, the pres- 


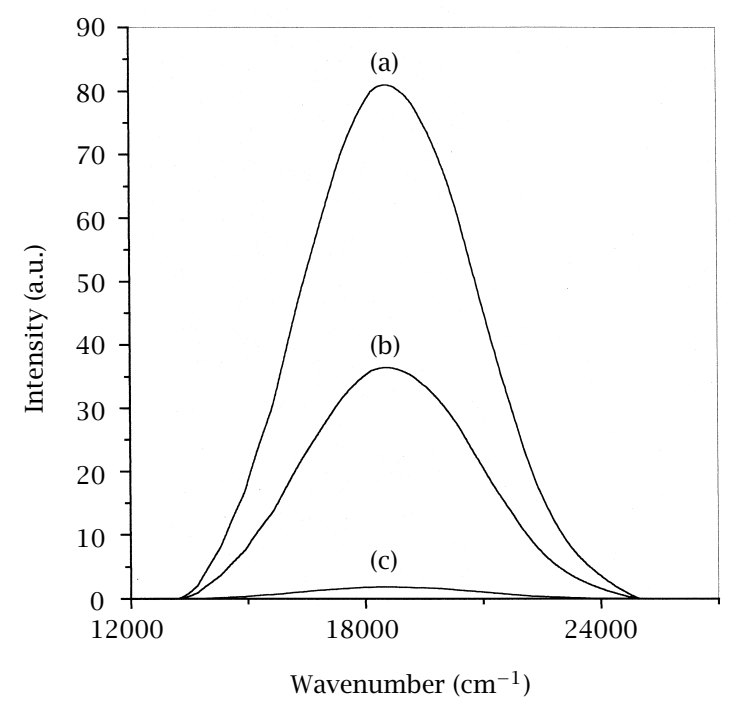

Figure 5. Recombination luminescence spectra of $2 \times 10^{-4} \mathrm{M}$ $\mathrm{CdS}$ nanoparticles in 2-propanol in the absence and presence of $\mathrm{Eu}^{3+}$-ions: (a) $0 \mathrm{M}$, (b) $5 \times 10^{-6} \mathrm{M}$, (c) $4 \times 10^{-5} \mathrm{M}$. Excitation wavelength $360 \mathrm{~nm}$.

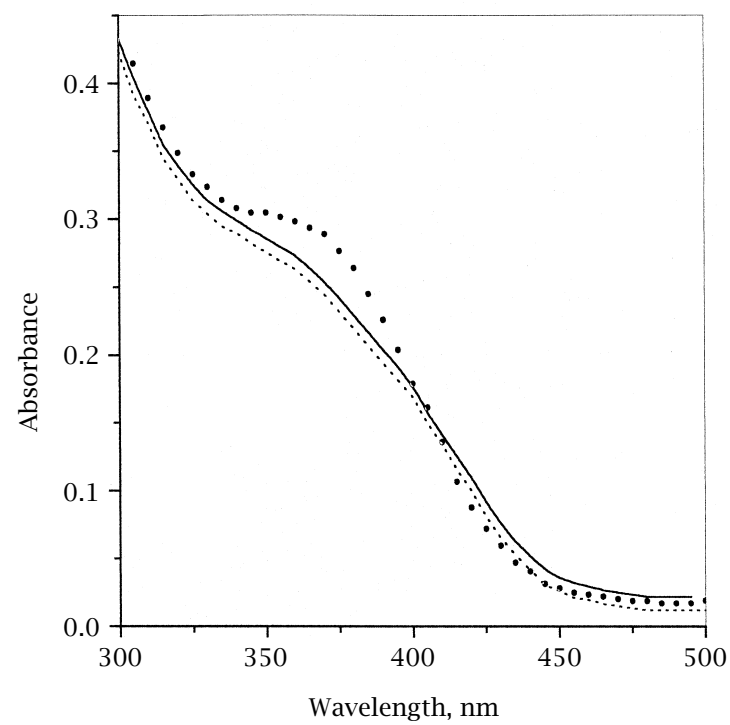

Figure 6. Absorption spectra of $2 \times 10^{-4} \mathrm{M}$ nonstoichiometric CdS nanoparticles in the absence and presence of $\mathrm{Eu}^{3+}$. ions: $0 \mathrm{M}$ (solid line), $1 \times 10^{-5} \mathrm{M}$ (dashed line), $1 \times 10^{-3} \mathrm{M}$ (dots).

ence of $\mathrm{Eu}^{3+}$ did not affect the absorption bands at 630$850 \mathrm{~nm}$. The latter absorption bands increase with irradiation time in the early stages as it is shown in Figure 3. However, at longer irradiation periods these absorption bands become weaker and they disappear completely at irradiation times longer than 2 hours. Therefore, the free radicals which appear to be directly responsible for the EPR spectrum and indirectly responsible for the ap- pearance of the absorption bands at 630-850 nm (Figure 3), must be linked in this case to trapped photogenerated positive holes since photogenerated electrons have been completely removed by $\mathrm{Eu}^{3+}$ ions.

We have recently shown that the presence of copper(II) ions bound onto the surface of CdS nanoparticles retards the photodecomposition of copper(II) tetraphenylporphyrin induced by CdS nanoparticles since adsorbed copper(II) ions facilitate electron/hole nonradiative annihilation [3, (e),(f)]. It was also found that the presence of copper(II) ions decelerates the photodecomposition of ZnTPP induced by CdS nanoparticles as well. Addition of $5 \times 10^{-6} \mathrm{M}$ copper(II) perchlorate to solutions containing $2 \times 10^{-4} \mathrm{M} \mathrm{CdS}$ and ZnTPP $\left(1 \times 10^{-4} \mathrm{M}\right.$ and $\left.2 \times 10^{-6} \mathrm{M}\right)$ stopped the photodecomposition of ZnTPP almost completely and prevented the formation of the above-mentioned paramagnetic species. Therefore, the formation of the EPR-active species, which precedes the formation of the intermediate products whose absorption spectra were outlined in Figure 3, appears to be connected to photogenerated holes in CdS nanoparticles.

The solvent (2-propanol) is oxidized effectively by $\mathrm{CdS}\left(\mathrm{h}^{+}\right)$[2, (a),(c)], [11, 12], leading to the formation of isopropyl radical.

$$
\begin{aligned}
& \mathrm{CdS}\left(\mathrm{h}^{+}{ }_{\text {tr. }}\right)+\left(\mathrm{CH}_{3}\right)_{2} \mathrm{CHOH} \\
& \quad \longrightarrow \mathrm{CdS}+\left(\mathrm{CH}_{3}\right)_{2} \mathrm{C}^{\bullet} \mathrm{OH}+\mathrm{H}^{+} \quad\left(\text { or }\left(\mathrm{CH}_{3}\right)_{2} \mathrm{C}^{\bullet} \mathrm{O}^{-}\right)
\end{aligned}
$$

The value of $\Delta G^{0}$ el.tr. for reaction (1) is nearly zero in the case of bulk CdS [11]:

$$
\begin{aligned}
\Delta \mathrm{G}^{0} \text { el.tr. }= & \mathrm{eE}^{0}\left(\left(\mathrm{CH}_{3}\right)_{2} \mathrm{C}^{\bullet} \mathrm{OH} /\left(\mathrm{CH}_{3}\right)_{2} \mathrm{CHOH}\right) \\
& -\mathrm{eE}^{0}\left(\mathrm{CdS}\left(\mathrm{h}^{+}\right) / \mathrm{CdS}\left(\mathrm{e}^{-} / \mathrm{h}^{+}\right)\right)-\mathrm{e}^{2} / \varepsilon \mathrm{R} \approx 0 \mathrm{eV} .
\end{aligned}
$$

However, reaction (1) is thermodynamically favored in the case of CdS nanoparticles because the redox potential of $\mathrm{CdS}\left(\mathrm{h}^{+}\right)$is more positive than that of bulk $\mathrm{CdS}\left(\mathrm{h}^{+}\right)$, i.e. $\Delta \mathrm{G}^{0}$ el.tr. $<0$. The isopropyl free radical formed is involved in additional reactions with molecular oxygen, both in the absence and in the presence of ZnTPP [13, 14]:

$$
\begin{aligned}
\left(\mathrm{CH}_{3}\right)_{2} \mathrm{C}^{\bullet} \mathrm{OH}+\mathrm{O}_{2} & \longrightarrow\left(\mathrm{CH}_{3}\right)_{2} \mathrm{C}\left(\mathrm{O}-\mathrm{O}^{\bullet}\right) \mathrm{OH} \\
& \longrightarrow\left(\mathrm{CH}_{3}\right)_{2} \mathrm{C}=\mathrm{O}+\mathrm{O}_{2}{ }^{-}+\mathrm{H}^{+} .
\end{aligned}
$$

The superoxide ions formed react further with 2propanol, leading to the formation of additional isopropyl radicals [14]:

$$
\left(\mathrm{CH}_{3}\right)_{2} \mathrm{CHOH}+\mathrm{O}_{2}{ }^{-}+\mathrm{H}^{+} \longrightarrow\left(\mathrm{CH}_{3}\right)_{2} \mathrm{C}^{\bullet} \mathrm{OH}+\mathrm{H}_{2} \mathrm{O}_{2} \text {. }
$$

Additional superoxide ions may be formed by electron transfer from the conduction band of photoexcited cadmium sulfide nanoparticles to molecular oxygen $[14,15]$ :

$$
\operatorname{CdS}\left(\mathrm{e}^{-}{ }_{\mathrm{CB}} / \mathrm{h}^{+}{ }_{\mathrm{VB}}\right)+\mathrm{O}_{2} \longrightarrow \mathrm{CdS}\left(\mathrm{h}^{+}{ }_{\mathrm{VB}}\right)+\mathrm{O}_{2}{ }^{-} \text {. }
$$


However, the contribution of reaction (4) to reaction (3) may be very limited based upon the limited quenching of the recombination luminescence of $\mathrm{CdS}\left(\mathrm{e}^{-} / \mathrm{h}^{+}\right)$by molecular oxygen.

The isopropyl radicals formed must be short lived because they were not detected by EPR. It should be emphasized that no EPR signal was detected in either control experiment. In the presence of ZnTPP, isopropyl radicals (both neutral and anionic) react with metalloporphyrin molecules, leading to the formation of zinc tetraphenylporphyrin radical anions [16]:

$\mathrm{ZnTPP}+\left(\mathrm{CH}_{3}\right)_{2} \mathrm{C}^{\bullet} \mathrm{OH} \longrightarrow \mathrm{ZnTPP}^{\bullet-}+\left(\mathrm{CH}_{3}\right)_{2} \mathrm{CO}+\mathrm{H}^{+}$,

$\mathrm{ZnTPP}+\left(\mathrm{CH}_{3}\right)_{2} \mathrm{C}^{\bullet} \mathrm{O}^{-} \longrightarrow \mathrm{ZnTPP}^{\bullet-}+\left(\mathrm{CH}_{3}\right)_{2} \mathrm{CO}$.

Reactions (5) and (6) involve oxidation of the isopropyl radicals to acetone by a thermodynamically allowed process:

$$
\begin{aligned}
\Delta \mathrm{G}^{0} \text { el.tr. }= & \mathrm{eE}^{0}\left(\left(\mathrm{CH}_{3}\right)_{2} \mathrm{CO} /\left(\mathrm{CH}_{3}\right)_{2} \mathrm{C}^{\bullet} \mathrm{O}^{-}\right) \\
& -\mathrm{eE}^{0}\left(\mathrm{ZnTPP} / \mathrm{ZnTPP}^{-}\right)-\mathrm{e}^{2} / \varepsilon \mathrm{R} \\
\approx & -0.5 \mathrm{eV}
\end{aligned}
$$

based upon $\mathrm{E}^{0}\left(\left(\mathrm{CH}_{3}\right)_{2} \mathrm{CO} /\left(\mathrm{CH}_{3}\right)_{2} \mathrm{C}^{\bullet} \mathrm{O}^{-}\right)=-1.52 \mathrm{~V}$ (vs. SCE). The $\pi$-radical anion of ZnTPP is formed mostly in the solution although it may be adsorbed onto the surface of CdS nanoparticles, CdS - ZnTPP•- ${ }^{\bullet}$ If ZnTPP•were mainly responsible for the EPR signal it would have also been observed in deaerated systems. However, the EPR signal is observed only in the presence of $\mathrm{O}_{2}$ and ZnTPP. Therefore, ZnTPP ${ }^{\bullet-}$ must be involved in further reactions with $\mathrm{O}_{2}$.

$$
\begin{aligned}
\mathrm{ZnTPP}^{\bullet-}+\mathrm{O}_{2} & \longrightarrow \text { superoxide intermediate species } \\
& \longrightarrow \text { products. }
\end{aligned}
$$

The formation of superoxide intermediates, in solution or adsorbed onto the surface of CdS nanoparticles, appear to be responsible for the EPR signal observed. In addition, it may be partly responsible for the absorbance of the irradiated sample in the range of 450-500 nm. This absorption shoulder appears immediately upon irradiation of the air-saturated mixture of CdS and ZnTPP, before the appearance of the weaker absorption bands at $630-850 \mathrm{~nm}$. Therefore, the free radical which is responsible for the EPR signal is not $\mathrm{ZnTPP}^{\bullet-}$ but either a combination of ZnTPP ${ }^{\bullet-}$ and $\mathrm{O}_{2}$, $\left(\mathrm{ZnTPP}-\mathrm{O}_{2}\right)^{-}$, or a similar free radical formed by the reaction of $\mathrm{O}_{2}{ }^{-}$with $\mathrm{ZnTPP}$, although the latter reaction is not very likely [17]. Furthemore, such paramagnetic species are not directly linked to the absorption bands at $630-800 \mathrm{~nm}$, because they have very short lifetime. No EPR signals were detected in mixtures of ZnTPP and CdS nanoparticles, irradiated and kept at room temperature, under the conditions described above, although such irradiation conditions led to fairly strong absorption bands in the spectral range of 630-850 nm (Figure 3). The latter absorption bands are attributed to intermediate diamagnetic photoproducts $[3,(d)]$, resulting from further transformations of the superoxide intermediates.

\section{CONCLUSIONS}

Photodecomposition of ZnTPP in the presence of $\mathrm{CdS}\left(\mathrm{e}^{-}\right.$св $\left./ \mathrm{h}^{+}{ }_{\text {VB }}\right)$ nanoparticles and molecular oxygen in 2-propanol is linked primarily to the reaction of ZnTPP with isopropyl free radicals, formed by both hole transfer from $\mathrm{CdS}\left(\mathrm{h}^{+}\right)$to $\left(\mathrm{CH}_{3}\right)_{2} \mathrm{CHOH}$ and the reaction of $\mathrm{O}_{2}{ }^{-}$with 2-propanol. Isopropyl free radicals react with ZnTPP, leading to ZnTPP•- which in the presence of $\mathrm{O}_{2}$ forms relatively stable EPR-active intermediates. Further transformations of such EPR-active species lead to the formation of diamagnetic intermediate photoproducts linked to the weak absorption bands observed in the spectral range of $630-800 \mathrm{~nm}$. The final photoproducts do not exhibit absorption bands in this range.

\section{ACKNOWLEDGEMENTS}

Financial support for this project by The University of Toledo is gratefully acknowledged.

\section{REFERENCES}

[1] (a) A. Henglein, Pure Appl. Chem. 56 (1984), 1215. (b) P. V. Kamat, Chem. Rev. 93 (1993), 267. (c) M. A. Fox and M. T. Dulay, Chem. Rev. 93 (1993), 341.

(d) Y. Wang, Advances in Photochemistry 19 (1995), 179.

(e) P. V. Kamat, Progress in Inorganic Chemistry 44 (1997), 273.

(f) D. Beydoun, R. Amal, G. Low, and S. J. McEvoy, Nanoparticle Research 1 (1999), 439.

(g) J. Z. J. Zhang, Phys. Chem. 104 (2000), 7239.

[2] (a) B. Ohtani, S. Tsuru, S. Nishimoto, T. Kagiya, and K. Izawa, J. Org. Chem., 55 (1990), 5551.

(b) B. Ohtani, S. Kusakabe, K. Okada, S. Tsuru, K. Izawa, Y. Amino, and S. Nishimoto, Tetrahedron Lett. 36 (1995), 3189.

(c) S. Yanagida, H. Kawakami, Y. Midori, H. Kizumoto, C. Pac, and Y. Wada, Bull. Chem. Soc. Jpn. 68 (1995), 1811.

(d) Y. Nakaoka and Y. Nosaka, J. Phys. Chem. 99 (1995), 9893.

(e) J. A. Navio, C. Cerrillos, F. J. Marchena, F. Pablos, and M. A. Pradera, Langmuir 12 (1996), 2007.

(f) Y. Nosaka, K. Koenuma, K. Ushida, and A. Kira, Langmuir 12 (1996), 736.

(g) F. Forouzan, T. C. Richards, and A. J. Bard, J. 
Phys. Chem. 100 (1996), 18123.

(h) Y. Nakaoka and Y. Nosaka, Langmuir 13 (1997), 708.

(i) V. Kurshev and L. Kevan, Langmuir 13 (1997), 225.

(j) A. Kumar, S. Kumar, and D. P. S. Negi, J. Chem. Res. 1 (1998), 54.

(k) A. Kumar and S. Kumar, J. Phys. Org. Chem. 11 (1998), 277.

(l) J. Choi, K. Yeo, M. Yoon, S. J. Lee, and K. Kim, J. Photochem. Photobiol., A-Chemistry 132 (2000), 105.

[3] (a) J. Chrysochoos, Mol. Cryst. Liq. Cryst 194 (1991), 247.

(b) J. Chrysochoos, J. Phys. Chem. 96 (1992), 2868. (c) Bhamro and J. Chrysochoos, J. Lumin. 60\&61 (1994), 359.

(d) Bhamro and J. Chrysochoos, J. Photochem. Photobiol., A-Chemistry 111 (1997), 187.

(e) A. V. Isarov and J. Chrysochoos, Langmuir 13 (1997), 3142.

(f) A. V. Isarov and J. Chrysochoos, Proc. Indian Acad. Sci., Chemical Sciences 110 (1998), 277.

[4] (a) A. Ivanisevic and A. B. Ellis, J. Phys. Chem. 103 (1999), 1914.

(b) G. Ashkenasy, A. Ivanisevic, R. Cohen, C. E. Felder, D. Cahen, A. B. Ellis, and A. Shanzer, J. Am. Chem. Soc. 122 (2000), 1116.

(c) A. Ivanisevic, M. F. Reynolds, J. N. Burstyn, and A. B. Ellis, J. Am. Chem. Soc. 122 (2000), 3731.

(d) A. Ivanisevic, A. B. Ellis, G. Ashkenasy, A. Shanzer, and Y. Rosenwaks, Langmuir 16 (2000), 7852.

(e) F. Seker, K. Meeker, T. Kuech, and A. B. Ellis, Chem. Rev. 100 (2000), 2505.

[5] (a) P. V. Kamat, J.-P. Chauvet, and R. W. Fessenden, J. Phys. Chem. 90 (1986), 1389.

(b) S. Suto, M. Yashima, W. Uchida, and T. Goto, J. Lumin. 38 (1987), 308.

(c) K. Kalyanasundaram, N. Vlachopoulos, V. Krishnan, A. Monnier, and M. Grätzel, J. Phys. Chem. 91 (1987), 2342.

(d) A. P. Hong, D. W. Bahnemann, and M. R. Hoffmann, J. Phys. Chem. 91 (1987), 2109, 6245.

(e) R. F. Khairutdinov, P. P. Levin, and S. M. B. Costa,
Langmuir 12 (1996), 714.

(f) H. H. Deng, Z. H. Lu, Y. C. Shen, H. F. Mao, and H. Xu, J. Chem. Phys. 231 (1998), 95.

(g) H. F. Mao, H. H. Deng, H. W. Li, Y. C. Shen, Z. H. Lu, and H. J. Xu, J. Photochem. Photobiol., AChemistry 114 (1998), 209.

(h) X. He, Y. Zhou, Y. Zhou, M. Zhang, and T. Shen, J. Coll. Int. Sci. 225 (2000), 128.

(i) Y. Tachibana, S. A. Haque, I. P. Mercer, J. R. Durrant, and D. R. Klug, J. Phys. Chem. 104 (2000), 1198.

[6] R. Rossetti, R. Hull, J. M. Gibson, and L. E. Brus, J. Chem. Phys. 82 (1985), 552.

[7] G. H. Barnett, M. F. Hudson, and K. M. Smith, Tetrahedron Lett. (1973), 2887.

[8] A. D. Adler, F. R. Longo, F. Kampas, and J. Kim, J. Inorg. Nucl. Chem. 32 (1970), 2443.

[9] R. H. Felton and H. Linschitz, J. Am. Chem. Soc. 88 (1966), 1113.

[10] (a) Y. F. Lee, M. Olshavsky, and J. Chrysochoos, J. Less-Common Met. 148 (1989), 259.

(b) J. Chrysochoos, J. Lumin. 48\&49 (1991), 709.

(c) J. Chrysochoos, K. Byene, J. Lumin. 81 (1999), 209.

[11] S. R. Morrison, The Chemical Physics of Surfaces, Plenum Press, New York, 1990.

[12] (a) A. Henglein, M. Gutiérrez, and Ch.-H. Fischer, Ber. Bunsenges. Phys. Chem. 88 (1984), 170.

(b) A. Fojtik, H. Weller, U. Koch, and A. Henglein, Ber. Bunsenges. Phys. Chem. 88 (1984), 969.

[13] P. Neta, Adv. Phys. Org. Chem. 12 (1976), 223.

[14] S. Yamagata, S. Nakabayashi, K. M. Sancier, and A. Fujishima, Bull. Chem. Soc. Jpn. 61 (1988), 3429.

[15] H. Noda, K. Oikawa, H. Ohya-Nishiguchi, and H. Kamada, Bull. Chem. Soc. Jpn. 66 (1993), 3542.

[16] (a) P. Neta, A. Scherz, and H. Levanon, J. Am. Chem. Soc. 101 (1979), 3624.

(b) G. S. Nahor, P. Neta, P. Hambright, L. R. Robinson, and A. Harriman, J. Phys. Chem. 94 (1990), 6659.

(c) D. M. Guldi, P. Hambright, D. Lexa, P. Neta, and J.-M. Savéant, J. Phys. Chem. 96 (1992), 4459.

[17] (a) J. S. Valentine, Y. Tatsuno, and M. Nappa, J. Am. Chem. Soc. 99 (1977), 3522.

(b) T. Ozawa and A. Hanaki, Inorg. Chim. Acta 80 (1983), 33. 


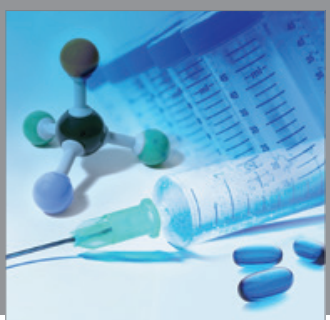

International Journal of

Medicinal Chemistry

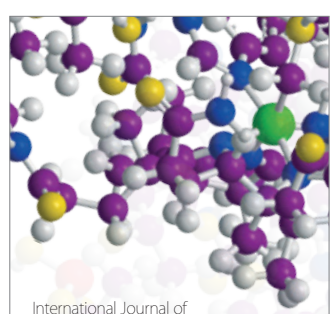

Carbohydrate Chemistry

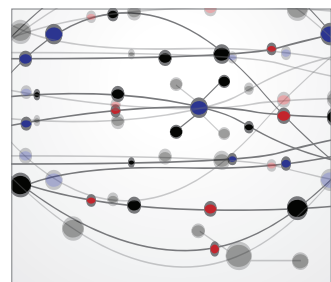

The Scientific World Journal
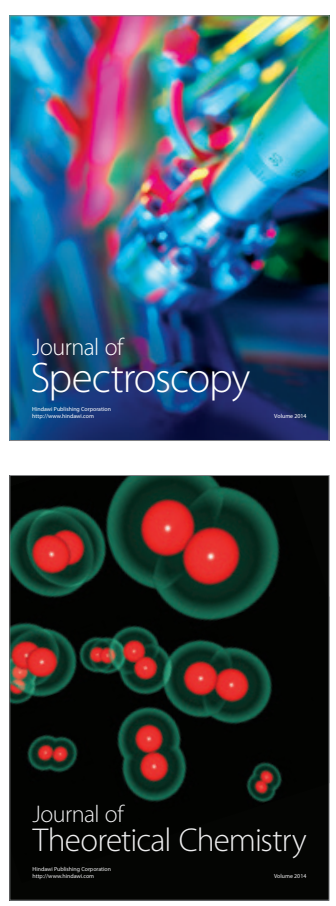
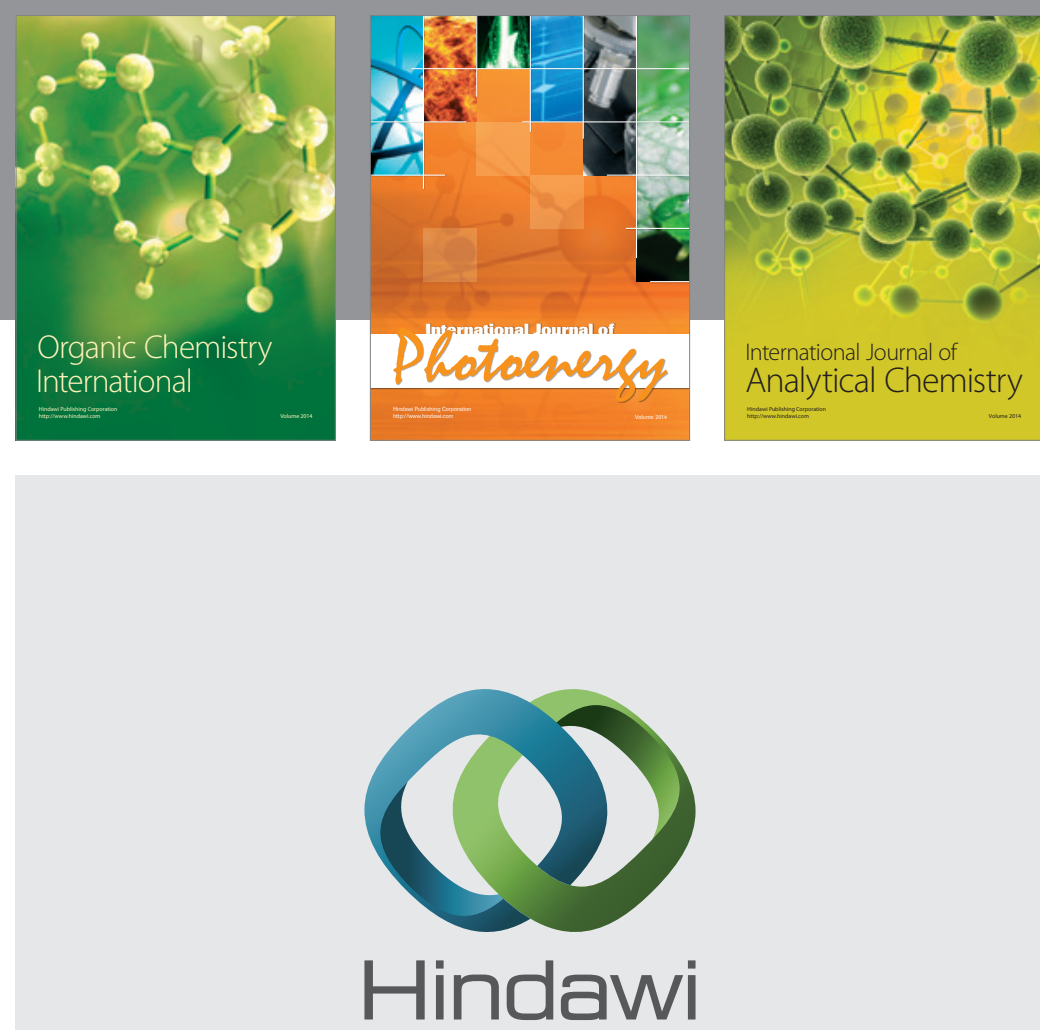

Submit your manuscripts at

http://www.hindawi.com
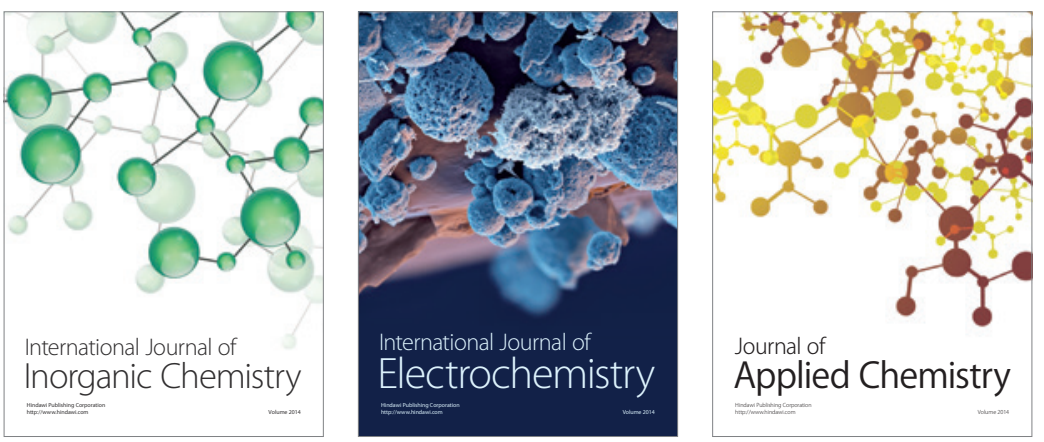

Journal of

Applied Chemistry
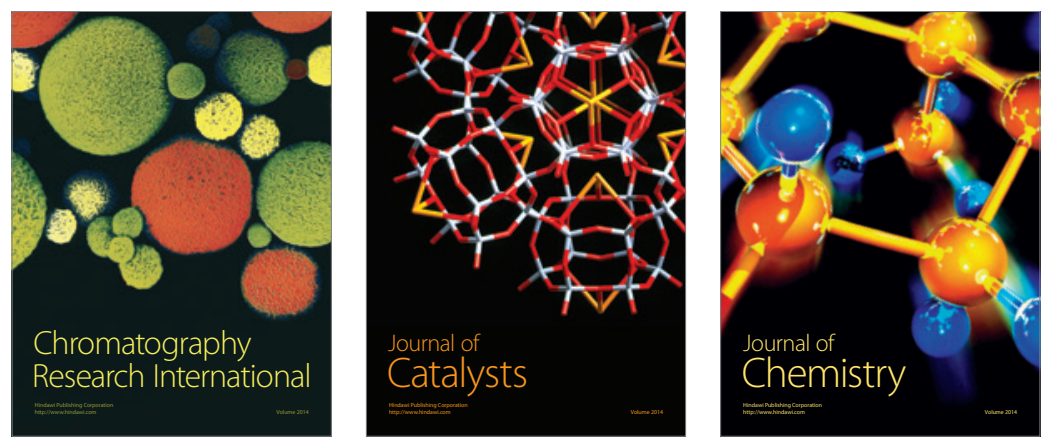
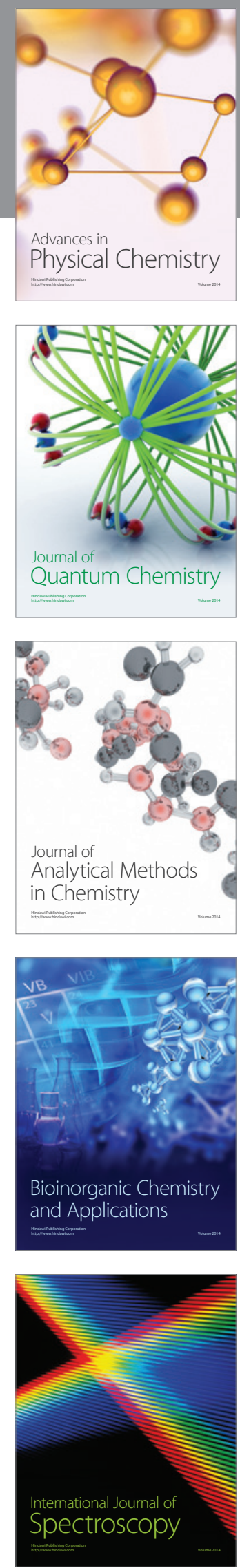